\title{
Neurosyphilis presenting with a stroke-like syndrome
}

\author{
Tarig Mohammed Abkur, Gasim Salaheldin Ahmed, Nidal Osman Alfaki, \\ Margaret O'Connor
}

Department of Internal Medicine, University Hospital Limerick, Limerick, Ireland

\section{Correspondence to Dr Tarig Mohammed Abkur, tarig1982@hotmail.com}

Accepted 9 February 2015
CrossMark

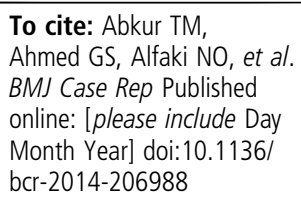

\section{SUMMARY}

Neurosyphilis results from infection of the central nervous system (CNS) by Treponema pallidum. Neurosyphilis can occur at any time after initial infection, particularly in immunocompromised patients. We describe a case of a 47-year-old man who presented with mixed dysphasia, right upper motor neuron facial palsy and right hemiparesis. Collateral history from the family revealed slowly progressive cognitive impairment and behavioural changes. Neuroimaging was unremarkable, suggesting a non-vascular aetiology. As there was no clear cause for the presentation, a lumbar puncture was performed and serum samples were sent for syphilis serology. The diagnosis of neurosyphilis was made on the basis of a positive RPR test in cerebrospinal fluid. The patient was treated with benzylpenicillin and made a full recovery, with restoration of cognitive function to baseline.

\section{BACKGROUND}

Diagnosis of neurosyphilis remains a challenge due to the frequent atypical presentations that are often indistinguishable from other diseases. The prognosis can be very good, with almost complete recovery if the appropriate therapy is started early.

\section{CASE PRESENTATION}

A right-handed 47-year-old man was brought to our facility by his neighbour. The neighbour found him wandering around the house, he was encephalopathic and was dysphasic with apraxia of speech. His medical history included depression for which he is on citalopram $20 \mathrm{mg}$ daily, although he had several depressive episodes in the preceding year despite treatment. His family reported behavioural changes and slowly progressive cognitive impairment.

On further questioning, he had been in a monogamous relationship with a female partner for the past 20 years; however, he mentioned to the family that he had previously been sexually abused as a child.

At presentation he was encephalopathic and was not orientated in time or place. In addition, he was dysphasic, and had a right upper motor neuron facial palsy and right hemiparesis. The limb weakness resolved rapidly over the next $30 \mathrm{~min}$ with persistence of dysphasia and facial palsy. National Institutes of Health Stroke Scale (NIHSS) was 6 initially and improved to four on repeat assessment after $30 \mathrm{~min}$. The patient was without fever and systemic examination was unremarkable.

\section{INVESTIGATIONS}

Initial laboratory studies were unremarkable except for elevated white cell count $13.6 \times 10^{9} / \mathrm{L}$ (neutrophils 11.7) and marginally raised $C$ reactive protein at $37 \mathrm{mg} / \mathrm{L}$. CT, MRI and MR angiography (MRA) of the brain were normal, no evidence of infarction was seen on diffusion-weighted imaging and the MRA did not support a diagnosis of cerebral vasculitis.

Investigations for a source of a suspected stroke included an echocardiogram, which showed normal left ventricular function with trace mitral regurgitation; a $24 \mathrm{~h}$ Holter monitor, with no arrhythmias found; ambulatory blood pressure, with no evidence of hypertension; and tests for serum glucose and cholesterol levels, both of which were within normal limits. Carotid Doppler ultrasound revealed bilateral extracranial carotid system atheromatous changes without haemodynamically significant stenosis.

As the aetiology of a suspected stroke could not be identified, further investigations for the cause of this stroke-like syndrome included a serum and cerebrospinal fluid (CSF) analysis of syphilis (table 1). The diagnosis of neurosyphilis was made on the basis of a reactive CSF rapid plasma regain (RPR). Serology for HIV was negative and autoantibody screen did not reveal any abnormalities.

\section{TREATMENT}

As the patient presented with a stroke-like syndrome, he was given $300 \mathrm{mg}$ of aspirin as haemorrhage had been excluded on a non-contrast axial CT brain. Thrombolysis was not considered due to rapid improvement in the neurological deficits.

On receipt of positive syphilis serology, treatment was initiated with intravenous benzylpenicillin (24 million units daily in six divided doses), for 17 days: as per UK National Syphilis Guidelines. ${ }^{1}$

\section{OUTCOME AND FOLLOW-UP}

There was a slow improvement in the patient's functional and cognitive status. The patient was discharged home on completion of the course of antibiotics, with a plan to re-analyse the CSF after an interval of 6 months. However, he presented to the emergency department within 4 weeks with a sudden onset severe headache. As part of the evaluation of this the lumbar puncture was carried out.

The patient made an excellent recovery 6 months after treatment, had a score of $29 / 30$ on the Mini-Mental State Examination (MMSE) and had no focal neurological deficits. CSF and serum samples were repeated and they showed evidence of successful treatment with resolution of the inflammatory markers in CSF. The serum RPR titre had fallen from 1 in 64 to 1 in 16. 
Table 1 Blood and CSF parameters before and after treatment with 17 days of intravenous benzylpenicillin

\begin{tabular}{llll}
\hline & June 2013 & July 2013 & $\begin{array}{l}\text { December } \\
2013\end{array}$ \\
\hline $\begin{array}{llll}\text { Blood } \\
\text { TPHA }\end{array}$ & $>10240$ & $>10240$ & $>10240$ \\
RPR & 1 in 64 & 1 in 32 & 1 in 16 \\
Syphilis Antibody CMIA & Positive & Positive & Positive \\
Syphilis IgM EIA & Positive & Positive & Positive \\
CSF & & & \\
White cells $(/ \mu \mathrm{L})$ & $56(100 \%$ & $30(100 \%$ & $<5$ \\
Red cells $(/ \mu \mathrm{L})$ & lymphocytes) & lymphocytes) & \\
Glucose $(\mathrm{mmol} / \mathrm{L})$ & 0 & 0 & 3 \\
Protein $(\mathrm{g} / \mathrm{L})$ & 2.9 & 2.8 & 3.4 \\
TPPA & 0.68 & 0.60 & 0.45 \\
RPR & $>1$ in 80 & $>1$ in 80 & $>1$ in 80 \\
\hline
\end{tabular}

CMIA, chemiluminescent microplate immunoassay; CSF, cerebrospinal fluid; EIA, enzyme immunoassay; RPR, rapid plasma reagin; TPHA, Treponema pallidum hemaglutination assay; TPPA, Treponema pallidum particle agglutination assay.

\section{DISCUSSION}

Syphilis is a sexually transmitted disease. It can be transmitted during primary or secondary stages with an efficiency of transmission of approximately $30 \% .^{2}$

Syphilis is often referred to as the Great Imitator, due to its frequent atypical presentation, which is often very similar to other diseases. When patients are untreated during the earlier stages of syphilis, they are at risk of serious complications involving the CNS, cardiovascular structures, skin or bone.

The neurological involvement occurs in less than $10 \%$ of untreated syphilis patients. ${ }^{3}$ Syphilis can affect the nervous system in many different ways. It may result in focal neurological deficits or global CNS dysfunction. The most common presentation is with neuropsychiatric manifestations. ${ }^{4}$ However, syphilis may also cause myelopathy, seizures, strokes, ocular disease and brain stem or cranial nerves abnormalities.

About $10 \%$ of patients with neurosyphilis and almost $3 \%$ of all syphilis patients present with a stroke. ${ }^{5}$ These patients tend to be younger than those with a stroke due to cardioembolism or atherosclerosis. In one study, up to $74 \%$ of this category of patients were under the age of $50 .^{78}$ Therefore, neurosyphilis should be considered in the evaluation of a young patient with a cryptogenic stroke.

Inflammatory infiltration of medium to large arteries is thought to be the mechanism underlying cerebral infarction in these cases. The middle cerebral artery is affected most frequently in neurosyphilis, which may result in a typical strokesyndrome. Less frequently, the posterior circulation may be involved. ${ }^{9}$ Compression of the left carotid artery by an enlarged thoracic aortic aneurysm has also been reported as a cause of stroke in patients with syphilis. ${ }^{10}$

The diagnosis of neurosyphilis requires a high degree of clinical suspicion. Lumbar puncture should be performed in suspected cases. A recently published Chinese study found comparable positive and negative predictive values between CSF Venereal Disease Research Laboratory (VDRL) tests, CSF-RPR tests and CSF toluidine red unheated serum tests (TRUST) among patients who are HIV negative. However, the specificity of CSF-VDRL (90.3\%) test was lower than that of the other tests $(92.7-93.4 \%) .^{11}$
A positive CSF VDRL or RPR test is considered diagnostic of neurosyphilis in the absence of substantial contamination of the CSF sample with blood. The number of red blood cells required to convert $1 \mathrm{~mL}$ of CSF is inversely related to the titre of VDRL in the blood. The amounts of red blood cells ranged between 202000 (for 1:4 titred blood) to 12000 (for 1:256 titred blood) per $1 \mathrm{~mL} .{ }^{12}$ The CSF VDRL test is very specific even in cases in which there are high serum VDRL or RPR titres (up to $1: 256$ ), and the results will be falsely positive only if blood contamination is sufficient to tinge CSF with blood. ${ }^{13}$

CSF examination should be repeated every 6 months after therapy if CSF pleocytosis is present on the initial sample. There is still controversy regarding the predictive value of serum RPR for prognosis of neurosyphilis.

PCR for detection of treponemal nucleic acids in the CSF has also been suggested to be useful and confirmatory. ${ }^{14}$ It has a sensitivity of $30-71 \%$ and a specificity of $93 \% .^{12} 15-17$

\section{Learning points}

- Neurosyphilis has a diverse clinical presentation that often mimics other diseases, both clinically and radiologically.

- Reactive cerebrospinal fluid (CSF) rapid plasma regain or Venereal Disease Research Laboratory (VDRL) in the absence of substantial contamination with blood is considered diagnostic for neurosyphilis. CSF VDRL may be falsely positive if blood contamination is sufficient to tinge the CSF with blood.

- Physicians should be aware of the potential neurological complications of neurosyphilis in view of the increasing incidence of the disease.

- Syphilis screening should be considered in the diagnostic work-up of young patients with a cryptogenic stroke.

Contributors TMA drafted the manuscript, performed the literature review and edited the final draft. GSGA and NOA helped with the literature review and editing of the article. MO edited the final draft.

Competing interests None.

Patient consent Obtained.

Provenance and peer review Not commissioned; externally peer reviewed.

\section{REFERENCES}

1 Kingston $M$, French $P$, Goh $B$, et al. UK national guidelines on the management of syphilis. Int J STD AIDS 2008;19:729-40.

2 Rockwell DH, Yobs AR, Moore MB Jr. The Tuskegee study of untreated syphilis; the 30th year of observation. Jr Arch Intern Med 1964;114:792-8.

3 Danielsen $A G$, Weismann $\mathrm{K}$, Jørgensen $\mathrm{BB}$, et al. Incidence, clinical presentation and treatment of neurosyphilis in Denmark 1980-1997. Acta Derm Venereol 2004;84:459-62.

4 Mitsonis CH, Kararizou E, Dimopoulos N, et al. Incidence and clinical presentation of neurosyphilis: a retrospective study of 81 cases. Int J Neurosci 2008;118:1251-7.

5 Hooshmand H, Escobar MR, Kopf SW. Neurosyphilis: study of 241 patients. JAMA 1972;219:726-9.

6 Singh AE, Romanowski B. Syphilis: review with emphasis on clinical, epidemiologic, and some biologic features. Clin Microbiol Rev 1999;12:187-209.

7 Merritt H, Adams R, Solomon H. Neurosyphilis. New York: Oxford University Press, 1946.

8 Kirkpatrick JB. Neurologic infections due to bacteria, fungi and parasites. In: Davis RL, Robertson DM., eds. Textbook of neuropathology. 2nd edn. Baltimore: Williams \& Wilkins, 1991:719-803.

9 Flint AC, Liberato BB, Anziska Y, et al. Meningovascular syphilis as a cause of basilar artery stenosis. Neurology 2005;64:391-2.

10 Nakane $H$, Okada $Y$, Ibayashi $S$, et al. Brain infarction caused by syphilitic aortic aneurysm. A case report. Angiology 1996;47:911-17.

11 Zhu L, Gu X, Peng RR, et al. Comparison of the cerebrospinal fluid (CSF) toluidine red unheated serum test and the CSF rapid plasma reagin test with the CSF venereal 
disease research laboratory test for diagnosis of neurosyphilis among HIV-negative syphilis patients in China. J Clin Microbiol 2014;52:736-40.

12 Hay PE, Clarke JR, Taylor-Robinson D, et al. Detection of treponemal DNA in the CSF of patients with syphilis and HIV infection using the polymerase chain reaction. Genitourin Med 1990;66:428-32.

13 Izzat NN, Bartruff JK, Glicksman JM, et al. Validity of the VDRL test on cerebrospinal fluid contaminated by blood. Br J Vener Dis 1971;47:162-4.

14 Morshed MG, Lee MK, Maguire J, et al. Neurosyphilitic gumma in a homosexual man with HIV infection confirmed by polymerase chain reaction. Int I STD AIDS 2008;19:568-9.
15 Noordhoek GT, Wolters EC, de Jonge ME, et al. Detection by polymerase chain reaction of Treponema pallidum DNA in cerebrospinal fluid from neurosyphilis patients before and after antibiotic treatment. J Clin Microbiol 1991;29:1976-84.

16 Gordon SM, Eaton ME, George R, et al. The response of symptomatic neurosyphilis to high-dose intravenous penicillin $\mathrm{G}$ in patients with human immunodeficiency virus infection. N Engl J Med 1994;331:1469-73.

17 Moskophidis M, Peters S. Comparison of intrathecal synthesis of Treponema pallidum- specific $\lg G$ antibodies and polymerase chain reaction for the diagnosis of neurosyphilis. Zentralb/ Bakteriol 1996;283:295-305.

Copyright 2015 BMJ Publishing Group. All rights reserved. For permission to reuse any of this content visit http://group.bmj.com/group/rights-licensing/permissions.

BMJ Case Report Fellows may re-use this article for personal use and teaching without any further permission.

Become a Fellow of BMJ Case Reports today and you can:

- Submit as many cases as you like

- Enjoy fast sympathetic peer review and rapid publication of accepted articles

- Access all the published articles

- Re-use any of the published material for personal use and teaching without further permission

For information on Institutional Fellowships contact consortiasales@bmjgroup.com

Visit casereports.bmj.com for more articles like this and to become a Fellow 